\title{
Is the adapted Radimer/Cornell questionnaire valid to measure food insecurity of urban households in Tehran, Iran?
}

\author{
Nahid Zerafati Shoae ${ }^{1, *}$, Nasrin Omidvar ${ }^{1}$, Mahmood Ghazi-Tabatabaie ${ }^{2}$, \\ Anahita Houshiar Rad ${ }^{3}$, Hajieh Fallah ${ }^{4}$ and Yadollah Mehrabi ${ }^{5}$ \\ 'Department of Community Nutrition, Faculty of Nutrition Sciences and Food Technology, Shahid Beheshti University \\ of Medical Sciences and Health Services, PO Box 19395-4741, Tehran, Iran: ${ }^{2}$ Department of Demography, Faculty \\ of Social Sciences, Tehran University, Tehran, Iran: ${ }^{3}$ Department of Nutritional Researches, National Nutrition and \\ Food Technology Research Institute, Shahid Beheshti University of Medical Sciences and Health Services, Tehran, \\ Iran: ${ }^{4}$ Statistical Research Center, Statistical Center of Iran, Tehran, Iran: ${ }^{5}$ Department of Community Medicine, \\ Faculty of Medicine, Shahid Beheshti University of Medical Sciences and Health Services, Tehran, Iran
}

Submitted 19 September 2005: Accepted 18 August 2006: First published online 14 May 2007

\begin{abstract}
Objective: To assess the validity of the adapted Radimer/Cornell questionnaire to measure food insecurity in low-income urban households in Tehran, the capital of Iran. Design: The Radimer/Cornell questionnaire was modified and used to assess the applicability, validity and reliability of such a measure in a culturally different context of urban households in Tehran. Factor analysis and Cronbach's $\alpha$ were used to assess validity and reliability, respectively. Socio-economic characteristics and food consumption frequency of the household were used to assess the criterion validity of the questionnaire.

Setting: District 20 of Tehran.

Subjects: A sample of 250 Iranian nuclear households with at least one child aged 1-18 years and a non-pregnant, non-lactating woman of reproductive age, selected through a multistage random sampling method.

Results: Three scales, labelled as household, individual and child hunger, were extracted through factor analysis using varimax rotation. Internal consistency of the scales was $0.897,0.820$ and 0.796 , respectively. Individual insecurity and child hunger were inversely correlated with monthly per capita income, father's education, mother's education and father's occupational status, and positively correlated with household size, as expected. However, household insecurity did not follow the same pattern. Consumption frequency of fruits, vegetables, dairy, red meat and rice declined as food insecurity status worsened, while bread and potato consumption increased.

Conclusion: The results show that a modified version of the Radimer/Cornell questionnaire is a valid and reliable instrument to measure household food insecurity in a culturally different context. However, further modifications seem necessary to measure food insecurity at household level. Results lend support to the utility and applicability of experience-based measures in varying cultural communities.
\end{abstract}

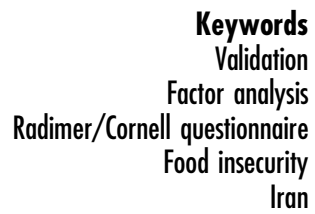

Keywords

Validation

questionnaire

Iran
Adequate nutrition and food security are fundamental elements of health and well-being, and considered one of the primary basic human needs. Food security is defined as: 'Access by all people at all times to enough food for an active, healthy life' ${ }^{\prime}$. About 800 million people - one-sixth of the developing world's population - do not have access to sufficient food to lead healthy, productive lives ${ }^{2}$.

In Iran, $20 \%$ of the population suffers from energy and protein insufficiency, while the prevalence of micronutrient insufficiency is estimated to be much higher ${ }^{3}$. This problem can lead to suboptimal quality of life as well as reduced physical, social and mental well-being ${ }^{4-6}$. Thus monitoring of community food security is necessary for planning appropriate programmes. Such measures can serve to monitor and evaluate the effectiveness of relief programmes, such as food subsidies, and to facilitate planning and targeting decisions.

In Iran, owing to the current absence of suitable, simple, low-cost and accurate tools, several indirect indicators are being used to measure food insecurity, including income, food intake and nutritional status. However, these indirect indicators are not specific and do not measure important aspects of the food insecurity experience ${ }^{7}$. Therefore, development of a valid, reliable and simple method to 
measure food insecurity and hunger is considered a priority for programme planners and policy-makers at community, local and national level.

One of the widely used measures of food security is the 12-item questionnaire developed by Radimer/Cornell ${ }^{8,9}$. The items in this tool seemingly can capture most food insecurity components and the tool has been shown as highly reliable and valid in households with children ${ }^{10-13}$. However, because of social and cultural differences, it is argued that such tools - which are designed to measure psychosocial phenomena in Western communities should be thoroughly validated and their reliability assessed before they can be applied in cross-cultural settings ${ }^{14-16}$. Studdert et al. found an adapted version of the Radimer/Cornell questionnaire to be valid and applicable in assessing food insecurity in households in Java, Indonesia ${ }^{17}$. However, further research is warranted to validate this tool in various cultural and economic settings. Thus the present study aimed to validate an adapted Radimer/Cornell questionnaire in assessing the food security of poor urban households in the city of Tehran, Iran.

\section{Methods}

\section{Radimer/Cornell questionnaire adaptation}

The 12-item Radimer/Cornell questionnaire ${ }^{11}$ was translated into Farsi and then modified through semi-structured interviews with 30 women who participated in Komiteh Emdad Imam Khomeini (KEIK) in district 20 of the city of Tehran. KEIK is a relief centre for households who are identified as low-income and at-risk, including low-income female-headed households. In adaptation we did not remove any statement; rather we minimised the ambiguity of the questions and provided alternative wording based on the feedback received during the interviews. We also added six questions to the original questionnaire (Q2, Q3, Q5, Q8, Q11 and Q14). In each interview, the respondents were asked whether they thoroughly understood the questions and if they had any suggestions on the wording and content of the questions. Based on these interviews, the following modifications were made to the original items.

- The phrase 'a balanced meal' and 'properly' were replaced with 'nutritious food' (Table 1).

- To transmit the concept more thoroughly, three extra items were added to the original questionnaire (Q2, Q3 and Q5).

- Three more items were deemed necessary by the respondents, to reflect the experience and perception of hunger and food insecurity (Q8, Q11 and Q14).

- The verb tenses of questions were changed and the wording of most questions was modified.

The modified questionnaire was reviewed and confirmed by a panel of six experts in the field of nutrition and social sciences.

\section{Pilot study}

The instrument was a questionnaire composed of four sections: (1) sociodemographic characteristics; (2) income; (3) a food-frequency questionnaire (FFQ); and (4) the adapted Radimer/Cornell questionnaire.

The primary food list in the FFQ was developed using previous dietary surveys $s^{3,18-20}$ and key informants. Special emphasis was given to foods with higher income elasticity. The initial FFQ consisted of 55 items, including six groups: (1) bread and cereals, (2) grains, (3) meats, (4) dairy, (5) vegetables and (6) fruits. After the pre-test, some of the food items in the FFQ were revised and some other items were added. The final FFQ included 64 items.

Table 1 Food insecurity questionnaire items: English back-translation from Farsi

\begin{tabular}{l}
\hline Item (during the last 12 months) \\
\hline 1. I have been worried that our food runs out and I don't have any money to buy it again \\
2.* I have been worried that due to lack of money I would not be able to buy enough food \\
3.* I have been thinking that I wish I had more money and I could buy more food \\
4. $\quad$ The food that I buy runs out very soon because I don't have money to buy enough \\
$5 .{ }^{*} \quad$ I can't make any food that I like, because the materials needed to make it have run out, and I don't have money to buy \\
them again \\
6. When I want to make a meal, the materials needed for making it have run out and I don't have enough money to buy it \\
7. $\quad$ We eat same food for several days in a row, because we don't have enough money to buy different kind of food \\
8.* I only make a few kind of cheap food and can't make different food because I don't have enough money \\
9. $\quad$ Due to lack of money I can't make enough food, so I eat less food \\
10. I can't eat nutritious food because I don't have money to buy it \\
11.* Due to lack of money and enough food, I only eat bread \\
12. Due to lack of enough food and money, I remain hungry and don't eat anything \\
13. I can't feed my child/children nutritious food because I don't have enough money \\
14. $\quad$ Sometimes my child/children only have bread because I don't have money to buy more of other foods \\
15. I know that my child/children sometimes is/are hungry but I don't have money to buy more food \\
16. My child/children don't eat enough food because I don't have enough money to buy food
\end{tabular}

${ }^{*}$ Items added to the adapted version of the Radimer/Cornell questionnaire. 
The instrument was pre-tested in a sample of 15 women from households within the community who were similar to the study sample.

\section{Study population and sampling}

The study was performed in district 20 of the city of Tehran. This district, which is located in the south of Tehran, is ranked as an area with low socio-economic status $^{21}$. Based on the estimated prevalence of hunger in $\mathrm{Iran}^{3}$, a sample of 250 households was selected. Sampling was carried out in three stages. In the first stage, the district was divided into three socio-economic zones (low, middle and high). Stratification was performed via informal queries to native staff from the health centre of the district and KEIK, who were familiar with the area. Eventually, four zones (two low, one middle, one high) were selected. In the second stage, clusters in the defined zones were selected. In the third stage, in each defined cluster six households were selected through a systematic random sampling method. Household selection criteria included being an Iranian, non-immigrant, nuclear family; the presence of a non-pregnant, non-lactating woman of childbearing age; a minimum of one child aged 1-18 years; and willingness to sign a consent form to participate in the study.

\section{Data collection}

Data were collected by a trained graduate nutrition student and N.Z.S., who were accompanied by local health volunteers, from January to March 2003. Interviews were conducted at the respondent's residence. The average time for each interview was about $45 \mathrm{~min}$. At the beginning of each interview, the goals of the study were introduced and the confidentiality of the answers was assured. Interviewers did not offer any economic incentive to the respondents and clearly explained to them that the information provided would not be used in any decision concerning food assistance or social benefits.

\section{Statistical analysis}

The respondents were categorised into four categories, based on following rules.

- Household secure: answered 'not true' for all items related to hunger and food insecurity.

- Household insecure: answered 'sometimes true' or 'often true' in one or more items related to householdlevel food insecurity (Q1-Q8), but 'not true' in all adultor child-level items.

- Individual insecure: answered 'sometimes true' or 'often true' in one or more adult-level items (Q9-Q13).

- Child hunger: answered 'sometimes true' or 'often true' in child-level items (Q14-Q16).

Construct validity of the questionnaire was assessed using principal components factor analysis with varimax rotation. Reliability of the measures and internal consistency of the items were examined using Cronbach's $\alpha$ and part-to-part and part-to-all correlations. Criterion validity of the measures was assessed through cross-tabulation of income and sociodemographic characteristics by the above categories, and the $\chi^{2}$ test. One-way analysis of variance was used to compare income-related frequencies of food consumption. Income-related food consumption frequency items or groups were those food groups or items that had high and significant correlation with income. In cases where the association of income with a food group was not significant, the food items in that group that had a significant relationship with income were selected as the income-related food consumption frequency items. All analyses were conducted using SPSS for Windows (version 11.5).

\section{Results}

\section{Sample characteristics}

Survey respondents were women with an average age of $36 \pm 6.7$ years. The average household size was 5 . The mothers and fathers of most households had a primary level of education ( $45 \%$ and 39\%, respectively). The first quartile of monthly income was less than 320120 Rials (\$36) per capita and the highest income quartile was $>750000$ Rials (\$84) per capita.

\section{Construct validity}

Principal components and factor analysis with varimax rotation of the adapted Radimer/Cornell scale resulted in the extraction of three factors: the first contained items on food anxiety and food depletion, the second factor contained items about food intake inadequacy of adults and children and food intake insufficiency of adults, and the third factor was composed of items about food intake insufficiency of children (Table 2). In most cases the factor loadings of the items were as expected and similar to those reported in previous studies, with the exception of items 7 , 8 and 12. Items 7 and 8 were loaded on factor 1 instead of factor 2, and item 12 loaded on factor 3 instead of factor 2 . Each scale was analysed separately (Table 3 ). The results were according to our expectations.

\section{Internal consistency}

Cronbach's $\alpha$ was 0.897 for household security, 0.820 for individual insecure and 0.796 for the child hunger scales. In behavioural research, Cronbach's $\alpha$ of 0.70 or greater is considered desirable ${ }^{22}$. Therefore, all measures of the scale had a good internal consistency.

\section{Criterion-related validity}

Criterion-related validity was assessed by comparing results obtained from the adapted Radimer/Cornell questionnaire with demographic characteristics, monthly 


\begin{tabular}{|c|c|c|c|c|}
\hline \multirow[b]{2}{*}{ Item } & & \multicolumn{3}{|c|}{ Factor loading } \\
\hline & & 1 & 2 & 3 \\
\hline 1. & I have been worried that our food runs out and I don't have any money to buy it again & 0.830 & 0.267 & 0.127 \\
\hline 2. & I have been worried that due to lack of money I would not be able to buy enough food & 0.808 & 0.186 & 0.119 \\
\hline 3. & I have been thinking that I wish I had more money and I could buy more food & 0.750 & 0.113 & 0.183 \\
\hline 4. & The food that I buy runs out very soon because I don't have money to buy enough & 0.628 & 0.330 & 0.213 \\
\hline 5. & $\begin{array}{l}\text { I can't make any food that I like, because the materials needed to make it have run out, and I don't have } \\
\text { money to buy them again }\end{array}$ & 0.616 & 0.523 & \\
\hline 6. & $\begin{array}{l}\text { When I want to make a meal, the materials needed for making it have run out and I don't have enough } \\
\text { money to buy it }\end{array}$ & 0.599 & 0.484 & \\
\hline 9. & Due to lack of money I can't make enough food, so I eat less food & 0.211 & 0.746 & 0.301 \\
\hline 10. & I can't eat nutritious food because I don't have money to buy it & 0.364 & 0.688 & 0.125 \\
\hline 11. & Due to lack of money and enough food, I only eat bread & & 0.676 & 0.485 \\
\hline 7. & $\begin{array}{l}\text { We eat same food for several days in a row, because we don't have enough money } \\
\text { to buy different kind of food }\end{array}$ & 0.269 & 0.653 & 0.187 \\
\hline 8. & $\begin{array}{l}\text { I only make a few kind of cheap food and can't make different food because } \\
\text { I don't have enough money }\end{array}$ & 0.473 & 0.652 & 0.158 \\
\hline 13. & I can't feed my child/children nutritious food because I don't have enough money & 0.456 & 0.598 & 0.260 \\
\hline 14. & $\begin{array}{l}\text { Sometimes my child/children only have bread because I don't have money to } \\
\text { buy more of other foods }\end{array}$ & 0.131 & 0.172 & 0.878 \\
\hline 15. & I know that my child/children sometimes is/are hungry but I don't have money to buy more food & 0.192 & & 0.792 \\
\hline 16. & My child/children don't eat enough food because I don't have enough money to buy food & 0.120 & 0.362 & 0.672 \\
\hline 12. & Due to lack of enough food and money, I remain hungry and don't eat anything & 0.120 & 0.291 & 0.604 \\
\hline
\end{tabular}

per capita income and consumption frequency of incomerelated foods, including red meat, vegetables, fruit, dairy, bread, rice and potato. As pointed out by previous researchers $^{3,19}$, rice and potato consumption were inversely associated with income, while other food items were directly associated with it. Tables 4 and 5 show the associations between food insecurity groups and sociodemographic criteria. Adult food insecurity and child hunger were inversely associated with income, father's education, mother's education and occupational status of the father $(P \leq 0.001, P \leq 0.002, P \leq 0.013$ and $P \leq 0.001$, respectively), but directly associated with household size $(P \leq 0.001)$. Household insecurity was inversely associated with household size, but directly associated with mother's education, father's education, father's occupational status and income. Consumption frequency of fruits, vegetables, dairy, red meat and rice decreased progressively as food insecurity score increased, while consumption of bread and potato increased $(P \leq 0.001)$.

Table 3 Factor loadings for household food insecurity, adult food insecurity and child hunger scales, each scale analysed separately

Factor loading

\section{Household items}

1. I have been worried that our food runs out and I don't have any money to buy it again

2. I have been worried that due to lack of money I would not be able to buy enough food

3. I have been thinking that I wish I had more money and I could buy more food

0.685

4. The food that I buy runs out very soon because I don't have money to buy enough it

0.746

5. I can't make any food that I like, because the materials needed to make it have run out, and I don't have money to buy them again

6. When I want to make a meal, the materials needed for making it have run out and

0.827 I don't have enough money to buy it

7. We eat same food for several days in a row, because we don't have enough money to buy different kind of food

8. I only make a few kind of cheap food and can't make different food because I don't have enough money

0.655

0.784

Adult items

9. Due to lack of money I can't make enough food, so I eat less food

10. I can't eat nutritious food because I don't have money to buy it

11. Due to lack of money and enough food, I only eat bread

12. Due to lack of enough food and money, I remain hungry and don't eat anything

13. I can't feed my child/children nutritious food because I don't have enough money

0.770

0.827

0.625

Child items

14. Sometimes my child/children only have bread because I don't have money

0.790 to buy more of other foods

15. I know that my child/children sometimes is/are hungry but I don't have money to buy more food

16. My child/children don't eat enough food because I don't have enough money to buy food
0.881

0.841

0.822 
Table 4 Relationships between food security status and socio-economic and demographic characteristics (\%) in urban households, district 20 of city of Tehran

\begin{tabular}{|c|c|c|c|c|c|}
\hline & Food secure & $\begin{array}{l}\text { Household } \\
\text { insecure }\end{array}$ & & Adult insecure & Child hunger \\
\hline \multicolumn{6}{|l|}{ Household size } \\
\hline $3-4$ & 18.8 & 34.4 & & 32.3 & 14.6 \\
\hline $5-6$ & 18.5 & 26.1 & & 40.3 & 15.1 \\
\hline \multirow[t]{2}{*}{$\geq 7$} & 2.9 & 11.8 & & 41.2 & 44.1 \\
\hline & & & $\chi^{2}=23.58$ & \multicolumn{2}{|c|}{$P \leq 0.001$} \\
\hline \multicolumn{3}{|c|}{ Monthly per capita income (Rials) } & & & \\
\hline$\leq 320120$ & - & 13.6 & & 42.4 & 44.1 \\
\hline $320120-520140$ & 8.3 & 21.7 & & 50.0 & 20.0 \\
\hline $520140-750000$ & 18.0 & 41.0 & & 34.4 & 6.6 \\
\hline$\geq 750000$ & 41.4 & 32.8 & \multirow{3}{*}{$\chi^{2}=79.94$} & 19.0 & 6.9 \\
\hline & & & & \multicolumn{2}{|c|}{$P \leq 0.001$} \\
\hline \multicolumn{3}{|c|}{ Father's education (years) } & & & \\
\hline$\leq 5$ & 9.5 & 21.1 & & 40.0 & 29.5 \\
\hline $6-11$ & 19.5 & 28.7 & & 40.2 & 11.5 \\
\hline$\geq 12$ & 22.6 & 37.1 & & 30.6 & 9.7 \\
\hline & & & $\chi^{2}=20.7$ & \multicolumn{2}{|c|}{$P \leq 0.002$} \\
\hline \multicolumn{3}{|c|}{ Mother's education (years) } & & & \\
\hline$\leq 5$ & 12.4 & 20.4 & \multirow{5}{*}{$\chi^{2}=16.24$} & 40.7 & 26.5 \\
\hline $6-11$ & 17.3 & 35.8 & & 30.9 & 16.0 \\
\hline$\geq 12$ & 23.6 & 29.1 & & 40.0 & 7.3 \\
\hline & & & & \multicolumn{2}{|c|}{$P \leq 0.013$} \\
\hline \multicolumn{3}{|c|}{ Father's occupational status } & & & \\
\hline Low & 6.9 & 27.6 & & 48.3 & 17.2 \\
\hline Middle & 23.8 & 34.3 & & 32.9 & 9.1 \\
\hline High & 1.8 & 16.4 & & 41.8 & 40.0 \\
\hline & & & $\chi^{2}=41.5$ & \multicolumn{2}{|c|}{$P \leq 0.001$} \\
\hline
\end{tabular}

Table 5 Household frequency of food groups/items consumption by food security status ${ }^{*}$, district 20 of the city of Tehran

\begin{tabular}{lccrrr}
\hline $\begin{array}{l}\text { Frequency } \\
\text { of consumption } \\
\text { (times per week) }\end{array}$ & $\begin{array}{c}\text { Food secure } \\
(n=41)\end{array}$ & $\begin{array}{c}\text { Household insecure } \\
(n=68)\end{array}$ & $\begin{array}{c}\text { Adult insecure } \\
(n=93)\end{array}$ & $\begin{array}{r}\text { Child hunger } \\
(n=47)\end{array}$ & $P$-value† \\
\hline Bread & $14.77(5.17)$ & $15.38(4.85)$ & $17.6(4.19)$ & $19.66(4.41)$ & $<0.001$ \\
Rice & $9.12(3.71)$ & $7.93(3.59)$ & $5.71(3.21)$ & $4.39(2.66)$ & $<0.001$ \\
Red meat & $6.57(2.42)$ & $5.31(2.67)$ & $3.99(2.45)$ & $3.11(2.47)$ & $<0.001$ \\
Dairy & $19.94(8.37)$ & $18.84(7.56)$ & $15.03(8.67)$ & $10.7(5.65)$ & $<0.001$ \\
Vegetables & $26.88(15.23)$ & $23.92(11.81)$ & $18.66(9.60)$ & $15.01(7.66)$ & $<0.001$ \\
Potato & $3.24(1.90)$ & $4.27(2.70)$ & $5.65(3.93)$ & $5.48(3.53)$ & $<0.001$ \\
Fruits & $23.20(14.87)$ & $15.88(11.04)$ & $10.85(9.06)$ & $5.74(5.11)$ & $<0.001$ \\
\hline
\end{tabular}

* Values are mean (standard deviation).

$\dagger P$-value for the test across food insecurity groups.

\section{Discussion}

This paper describes the modification and validation of an adapted Radimer/Cornell questionnaire to measure household food insecurity in a low socio-economic community in the city of Tehran, Iran. It is the first attempts at validating a direct tool for the measurement of food security in Iranian households. Based on the findings, the questionnaire measured household food insecurity in three levels, labelled as household insecure, adult insecure and child hunger. Most of the items in the questionnaire loaded on the related scales, as expected, with the exception of 'Due to lack of enough food and money, I remain hungry and don't eat anything', 'We eat same food for several days in a row, because we don't have enough money to buy different kind of food' and 'I only make a few kind of cheap food and can't make different food because I don't have enough money'.

However, factor analysis of the items related to each scale separately resulted in a single underlying factor, indicating the relevance of the items to the underlying concept when considered separately. Further examination of the internal consistency and part-to-all correlations of each item indicated that these items contributed to the conceptual clarity and reliability of each scale when they remained in the scales.

The criterion-related validity of the items within measures of adult insecurity and child hunger was within our expectations; however, the household insecurity scale did not discriminate as expected.

Adapted versions of the Radimer/Cornell questionnaire and other experience-based measures of food insecurity, 
such as the CCHIP (Childhood Hunger Identification Project) and the CFSM (Core Food Security Measure), have successfully been applied and validated in various cultural and economic settings such as Indonesia ${ }^{17}$, Venezuela ${ }^{23}$, Brazil $^{24,25}$, Asians/Pacific Islanders ${ }^{26}$, India and Uganda ${ }^{27}$. Results of these studies are generally consistent with results of the original versions and lend support to the applicability and validity of adapted versions of these tools in crosscultural applications. Consistent with previous findings, the present study also lends general support to the validity and applicability of an adapted version of the Radimer/Cornell in the Iranian social, economic and cultural context. However, the findings show that the scale works more accurately at the level of adult food insecurity and child hunger, and further research is warranted to improve the applicability of the measure at household level.

There were two major limitations in the validation process. First, as pointed out by many researchers, in efforts to adapt an instrument in cross-cultural settings, careful translation of experience-based measures, coupled with cognitive testing, is necessary to achieve satisfactory results ${ }^{27}$. No such cognitive testing of the questionnaire was carried out. The second limitation involves the sample selected to carry out the modification of words and phrases. This was carried out through interviews with women who most probably had experienced high and moderate food insecurity; our sample did not included food-secure or marginally foodsecure cases. It would have been more desirable if a broad range of insecure to marginally secure cases was also included in the study. Despite our expectations, we observed that people were not reluctant or embarrassed to express their deprivation, even when it was expressed using the word 'hunger'.

We conclude that the adapted Radimer/Cornell questionnaire can be used to categorise food-secure and foodinsecure households in low-income urban communities in Iran. The applicability of this questionnaire to measure degrees of household food insecurity is promising for improving food and nutrition monitoring systems and the screening of relief programmes. However, further research is required to construct and validate the tool for subgroups of the population.

\section{Acknowledgements}

Sources of funding: This work was accomplished by financial support of N.Z.S.

Conflict of interest declaration: There is no conflict of interest.

Authorship responsibilities: N.Z.S. was the author of this paper. It was her thesis that was supervised by N.O. and M.G.-T., whose fields are community nutrition and social science, respectively. A.H.R., H.F. and Y.M. were her advisors, giving advice about food consumption, study design and data analyses, respectively.
Acknowledgements: The authors would like to thank Dr Nasser Mohammadi, who led to the initiation of this work, and Shahrzad Rokni for her encouragement. We thank Leila Kaboodanian for her cooperation in data collection and data entering. Also, the contribution of the women who participated in the study, the Komiteh Emdad Imam Khomeini and the health centre of district 20 of Tehran city is gratefully acknowledged.

\section{References}

1 Life Science Research Office; Anderson SA, ed. Federation of American Societies for Experimental Biology. Core indicators of nutritional status for difficult to sample population. Journal of Nutrition 1990; 120(11): 1557s-600s.

2 Pinstrup-Andersen P, Pandya-Lorch R, Rosegrant MW. Global food security: a review of the challenges. In: Pinstrup-Andersen P, Pandya-Lorch R, eds. The Unfinished Agenda: Perspectives on Overcoming Hunger, Poverty and Environmental Degradation. Washington, DC: International Food Policy Research Institute, 2001; 7-17.

3 Ghassemi H. Food and Nutrition Security in Iran: Studies of Planning and Implementation Models. Final report of research project. Tehran: National Nutrition and Food Technology Research Institute, 1998 [in Farsi].

4 Vailas LI, Nitzke SA, Becker M, Gast J. Risk indicators for malnutrition are associated inversely with quality of life for participants in meal programs for older adults. Journal of the American Dietetic Association 1998; 98(5): 548-53.

5 Campbell CC. Food insecurity: a nutritional outcome or a predictor variable? Journal of Nutrition 1991; 121(3): 407-15.

6 Pheley AM, Holben DH, Graham AS, Simpson C. Food security and perceptions of health among rural Appalachians. Journal of the American Dietetic Association 2000; 100(Suppl. 1): A-92.

7 Wolfe WS, Frongillo EA. Building household food-security measurement tools from the ground up. Food and Nutrition Bulletin 2001; 22(1): 5-12.

8 Radimer KL, Olson CM, Campbell CC. Development of indicators to assess hunger. Journal of Nutrition 1990; 120(Suppl. 11): 1544-8.

9 Radimer KL, Olson CM, Greene JC, Campbell CC, Habicht JP. Understanding hunger and developing indicators to assess it in women and children. Journal of Nutrition Education 1992; 24: 36S-44S

10 Kendall A, Olson CM, Frongillo EA Jr. Validation of the Radimer/Cornell Hunger and Food Insecurity Measures: Final Project Report to the New York State Department of Health. Ithaca, NY: Cornell University, 1994.

11 Kendall A, Olson CM, Frongillo EA Jr. Validation of the Radimer/Cornell measures of hunger and food insecurity. Journal of Nutrition 1995; 125(11): 2793-801.

12 Frongillo EA, Rauschenbach BS, Olson CM, Kendall A, Colmenares AG. Questionnaire-based measures are valid for the identification of rural households with hunger and food insecurity. Journal of Nutrition 1997; 127(5): 699-705.

13 Frongillo EA. Validation of measures of food insecurity and hunger. Journal of Nutrition 1999; 129(2S Suppl.): 506S-9S.

14 Kotobi M. Human problems research in social sciences. Nameb ye Olum e Ejtemai 1968; 1(1) [in Farsi].

15 Kotobi M. Survey of Western research method to contact of social and psychological problem in Iran. Nameh ye Olum e Ejtemai 1975; 2(3) [in Farsi].

16 Enriquez VG. Psychology in the Third World. Philippine Journal of Psychology 1977; 10: 3-14. 
17 Studdert LJ, Frongillo EA Jr, Valois P. Household food insecurity was prevalent in Java during Indonesia's economic crisis. Journal of Nutrition 2001; 131(10): 2685-91.

18 Amin-RashtiN. Economic status of women-headed housebolds. MA thesis, Islamic Azad University, Tehran, 1997 [in Farsi].

19 Samimi B, Djazayeri A, Siasi F, Mahmudi M, Vallaii N, Dorosti-Motlagh A. Final Report of Trend Consumption of Food, Energy and Some Nutrients during 1983-1993 in Iran. Tehran: National Nutrition and Food Technology Research Institute, 1995 [in Farsi].

20 Ghassemi H, Kimiagar M, Koopahi M. Household Food Security in Tehran Province. Tehran: National Nutrition and Food Technology Research Institute, 1996 [in Farsi].

21 Statistical Center of Iran. Statistical Year-book of Iran. Tehran: National Management and Planning Organization, 2001 [in Farsi].

22 Henerson ME, Morris LL, Fitz-Gibbon CT. How to Measure Attitudes. Beverly Hills, CA: Sage Publications, 1978.

23 Lorenzana PA, Sanjur D. Abbreviated measures of food sufficiency validly estimates the food security level of poor household: measuring household food security. Journal of Nutrition 1999; 129(3): 687-92.
24 Segall Correa AM, Perez-Escamilla R, Kurdian Maranha L, Sampaio F, Vianna R, Vieira-Freire L, et al. An adapted Version of the USDA food security scale is a valid tool to assess household food insecurity in urban areas in Brazil. FASEB Journal 2004; 18A: 488.

25 Perez-Escamilla R, Segall-Correa AM, Kurdian Maranha L, Sampaio Md Mde F, Marin-Leon L, Panigassi G. An adapted version of the US Department of Agriculture food insecurity module is a valid tool for assessing household food insecurity in Campinas, Brazil. Journal of Nutrition 2004; 134(8): 1923-8.

26 Derrickson JP, Fisher AG, Anderson JE. The core food security module scale measure is valid and reliable when used with Asians and Pacific Islanders. Journal of Nutrition 2000; 130(11): 2666-74.

27 Nord M, Satpathy AK, Ray N, Webb P, Houser R. Experiences in using qualitative methods for measuring food security. Comparing household survey-based measures of food insecurity across countries: case studies in India, Uganda and Bangladesh. In: Proceedings of International Scientific Symposium on Measurement and Assessment of Food Deprivation and Undernutrition. Rome: Food and Agriculture Organization of the United Nations, 2002; 297-9. 